\title{
Radiocarbon
}

1988

\section{GROWTH RATES OF NATURAL AMAZONIAN FOREST TREES BASED ON RADIOCARBON MEASUREMENTS}

\author{
A A MOZETO*, PETER FRITZ**, M Z MOREIRA†, E VETTER + , \\ RAMON ARAVENA**, ENEAS SALATI $\dagger$ and R J DRIMMIE**
}

ABSTRACT. Evergreen trees in the tropical rain forest of the Amazonas Basin can produce growth rings which are not necessarily related to annual events. Therefore, estimation of growth rate cannot be done by dendrochronology. This report presents a technique for determining the growth rate of these trees based on radiocarbon measurements of two segments of equal radial distance from the outer part of the tree trunk. The measured ${ }^{14} \mathrm{C}$ activity is compared to local ${ }^{14} \mathrm{C}$ fallout and growth rates are derived from models taking into account bomb ${ }^{14} \mathrm{C}$ effects. Eleven trees from various parts of the Amazon Basin were analyzed. The average growth rates range from ca 5 to $>40 \mathrm{yr}$ per centimeter corresponding to extrapolated ages from ca 60 to $>400 \mathrm{yr}$.

\section{INTRODUCTION}

Rings of trees growing in temperate climate permit accurate dating of forest stands and determination of growth rates. Such information cannot be obtained on evergreen trees from tropical rain forests. In the Amazonas region annual flooding does, however, cause some cyclicity in tree growth so that trees which defoliate during submersion show annual rings reflecting the cambial dormancy induced by lack of oxygen in the root zone. Growth rings of such trees are "often undefined and boundaries frequently run irregularly over the cross section" (Worbes, 1985).

In 1980 an international workshop was held to discuss "age and growth rate of tropical trees: new directions for research" (Borman \& Berlyn, 1980). It concluded that very few data exist but identified some promising avenues. Among others, Stuiver et al (1980) proposed to use radiocarbon to establish growth rates. The technique would take advantage of the anthropogenic input to the atmospheric radiocarbon reservoir and especially the maximum fallout in the Northern and Southern Hemisphere which followed nuclear testing in 1963/64. This suggestion was applied in modified form in this study.

The tree species reported in this study were selected based on the wood specific weight (ratio of dry weight/water saturated weight of the heartwood) and the diameter of tree trunk so as to select both old and young trees. The location and the time of cutting is known and species were

\footnotetext{
* Universidade Federal de Sao Carlos, Departamento de Química, Caixa Postal 676, 13560-Sao Carlos, SP, Brazil

** University of Waterloo, Department of Earth Sciences, Waterloo, Ontario, Canada N2L 3G1

+ Centro de Energia Nuclear na Agricultura, Universidade de Sao Paulo, Caixa Postal 96, 13400-Piracicaba, SP, Brazil

$\ddagger$ Instituto Nacional de Pesquisas da Amazônia, Centro de Pesquisas de Produtos Florestais, Caixa Postal 478, 69000-Manaus, AM, Brazil
} 
TABLE 1

${ }^{13} \mathrm{C}$ content and ${ }^{14} \mathrm{C}$ activity in two segments of equal radial distance sampled from the surface of the tree trunk of studied species

\begin{tabular}{|c|c|c|c|c|}
\hline \multirow[b]{2}{*}{ Tree no., species, sample loc } & \multicolumn{2}{|c|}{$\begin{array}{c}\delta^{13} \mathrm{C} \\
(\%, \mathrm{PDB})\end{array}$} & \multicolumn{2}{|c|}{$\begin{array}{c}\delta^{14} \mathrm{C} \text { activity } \\
\% 0 \text { modern } \pm 1 \sigma\end{array}$} \\
\hline & $0-\mathrm{X}$ & $\mathrm{X}-2 \mathrm{X}$ & $0-\mathrm{X}$ & $\mathrm{X}-2 \mathrm{X}$ \\
\hline 1-1 Lecythis usitata Miers (Manaus, AM) & -27.5 & -26.5 & $216.0 \pm 9.9$ & $4.6 \pm 8.3$ \\
\hline 1-3 Hymenaea sp (Manaus, AM) & -26.7 & -26.1 & $107.9 \pm 8.5$ & $-25.5 \pm 6.9$ \\
\hline 1-5 Dinizia excelsa Ducke (Manaus, AM) & -27.4 & -27.2 & $438.2 \pm 11.9$ & $285.6 \pm 10.8$ \\
\hline 1-6 Vatairea sp (Manaus, AM) & -26.1 & -26.4 & $144.2 \pm 7.4$ & $2.8 \pm 4.2$ \\
\hline 1-7 Calophyllum brasiliense Camp & & & & \\
\hline (Upper Purus R-Rio Branco, AC) & -27.0 & -26.4 & $217.3 \pm 11.4$ & $417.4 \pm 12.4$ \\
\hline 2-1 Parkia sp (Boa Vista, RR) & -27.3 & -26.6 & $364.8 \pm 11.3$ & $7.6 \pm 8.7$ \\
\hline 2-2 Hymenolobium pulcherrimum (Boa & & & & \\
\hline Vista, RR) & -27.1 & -27.0 & $334.1 \pm 10.9$ & $20.1 \pm 8.6$ \\
\hline *2-3 Hymenaea sp (Boa Vista, RR) & -27.4 & -27.2 & $277.0 \pm 11.4$ & $449.3 \pm 12.6$ \\
\hline 2-4 Dimzia sp (Porto Velho, RO) & -26.0 & -26.4 & $430.8 \pm 12.7$ & $341.7 \pm 12.2$ \\
\hline 2-5 Hymenolobium pulcherrimum & & & & \\
\hline (Porto Velho, RO) & -27.0 & -26.3 & $235.7 \pm 11.4$ & $0.7 \pm 9.5$ \\
\hline *2-6 Hymenaea sp (Porto Velho, RO) & -28.6 & -27.9 & $378.4 \pm 11.6$ & $408.4 \pm 11.8$ \\
\hline
\end{tabular}

* Sample segments for these trees are $4 \mathrm{~cm}$; all others are of $3 \mathrm{~cm}$ each.

collected in different parts of the Amazonas Basin as they represent different environments in terms of climate and vegetation.

\section{RESULTS AND DISCUSSION}

Table 1 shows the carbon isotope results obtained on samples from 11 Amazonian trees. The samples were extracted with acid-alc-acid solutions (AAA pretreatment) and the ${ }^{14} \mathrm{C}$ activity was measured on benzene by liquid scintillation counting. ${ }^{13} \mathrm{C}$ data were obtained on $\mathrm{CO}_{2}$ produced by combustion of AAA treated wood. The ${ }^{14} \mathrm{C}$ and ${ }^{13} \mathrm{C}$ results are expressed as delta per mil $(\delta \%)$ values with respect to the activity of standard oxalic acid in 1950 and $\mathrm{PDB}$, respectively.

Assuming that growth rates are constant, two segments of equal radial distance from the outer part of the tree trunk were collected for ${ }^{14} \mathrm{C}$ analyses (integrated samples) and named $0-\mathrm{X}$ and $\mathrm{X}-2 \mathrm{X}$. For constant growth rates they represent equal growth periods. The yearly growth rate can be derived from this once the growth period (years/X) has been determined. This is accomplished by matching the radiocarbon activities of the two equal segments with average values of ${ }^{14} \mathrm{C}$ fallout for consecutive equal lengths of time (see below).

The technique assumes that the fallout pattern for radiocarbon is known. Unfortunately, the data base for the Amazonas region is very limited and cannot be readily deduced from Northern or Southern Hemisphere data because their respective influence in this equatorial region is not well documented. However, based on a single data point, obtained by Polach and Singh (1980) as well as a few isolated measurements by us, an approximate fallout curve was constructed for the Amazon basin using as reference the Northern Hemisphere fallout curve presented by Levin et al 
TABLE 2

Plant ${ }^{14} \mathrm{C}$ activity $(\delta \%$ modern $)$ and averaged ${ }^{14} \mathrm{C}$ activity for periods $0-\mathrm{X}$ and $\mathrm{X}-2 \mathrm{X}$.

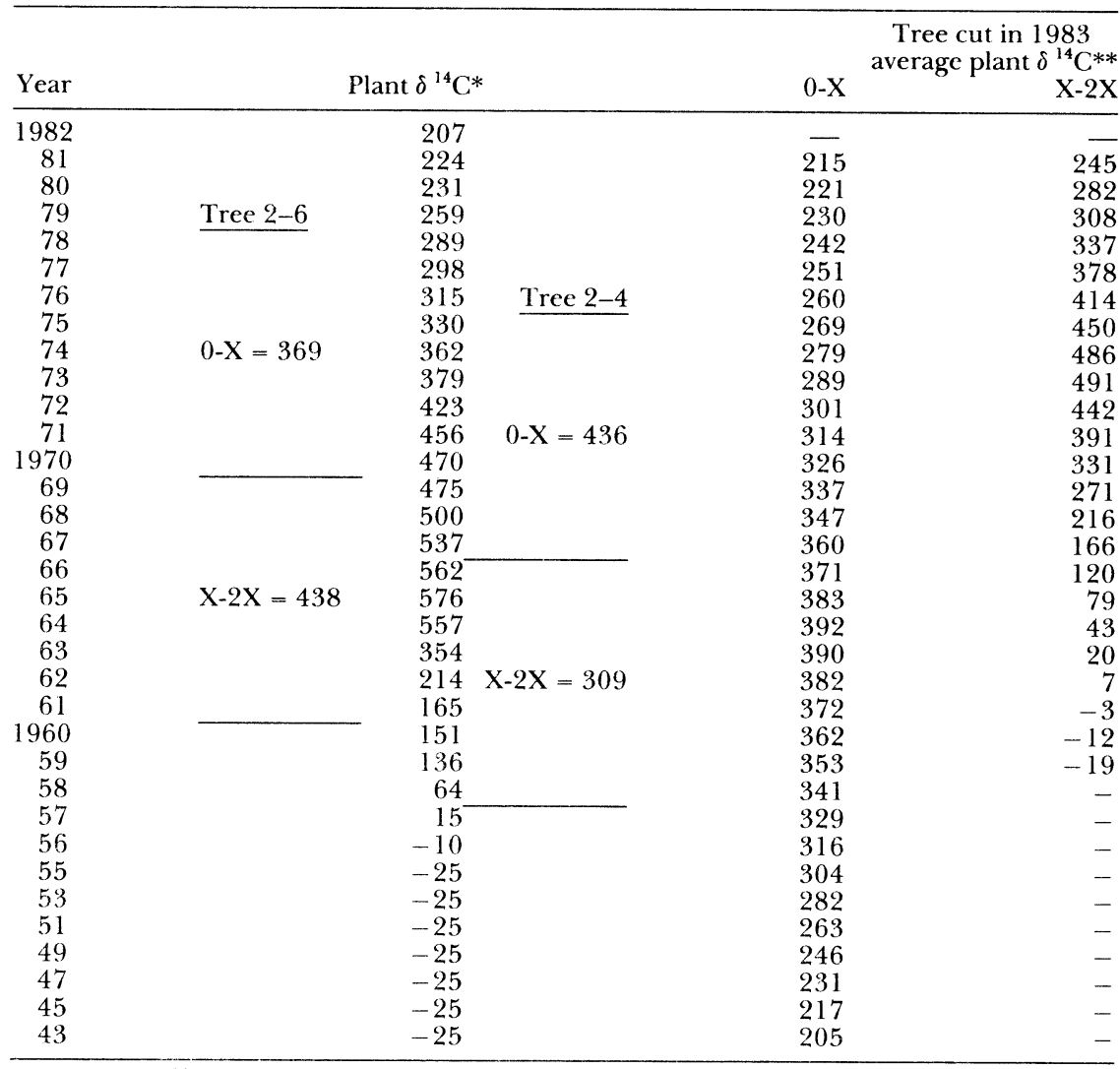

* Plant $\delta{ }^{14} \mathrm{C}$ are assumed yearly averages based on Northern Hemisphere fallout data.

** $0-\mathrm{X}$ and $\mathrm{X}-2 \mathrm{X}$ are average ${ }^{14} \mathrm{C}$ activities calculated over equal and sequential periods of time; eg, for $1976,0-\mathrm{X}$ records the average ${ }^{14} \mathrm{C}$ activity for the period $1982-1976(7 \mathrm{yr})$ and $\mathrm{X}-2 \mathrm{X}$ for the following $7-y \mathrm{r}$ average from 1975 to 1969 .

(1985). Attempts are in progress to obtain samples of known ages so that an Amazonian fallout curve can be constructed.

The average annual fallout values used in this study are shown in Table 2, converted into plant activities considering that carbon fixation during photosynthesis is accompanied by an isotopic fractionation. A value of 2.0 was used for the ratio $\in^{14} \mathrm{C} / \in^{13} \mathrm{C}$ (where $\in$ is the isotopic enrichment factor between $\mathrm{CO}_{2}$ and plant matter) in order to maintain agreement with other publications. It must be noted, however, that Saliège and Fontes (1984) experimentally determined a value of 2.3 for that ratio. The data for plant $\delta{ }^{14} \mathrm{C}$ in Table 2 are also normalized to a $\delta{ }^{13} \mathrm{C}=-25 \%$ using a value of $-8.5 \%$ for the atmospheric $\mathrm{CO}_{2}$ (Levin et al, 1985).

Growth periods (years $/ \mathrm{X}$ ) and growth rates (mm/year) were deter- 


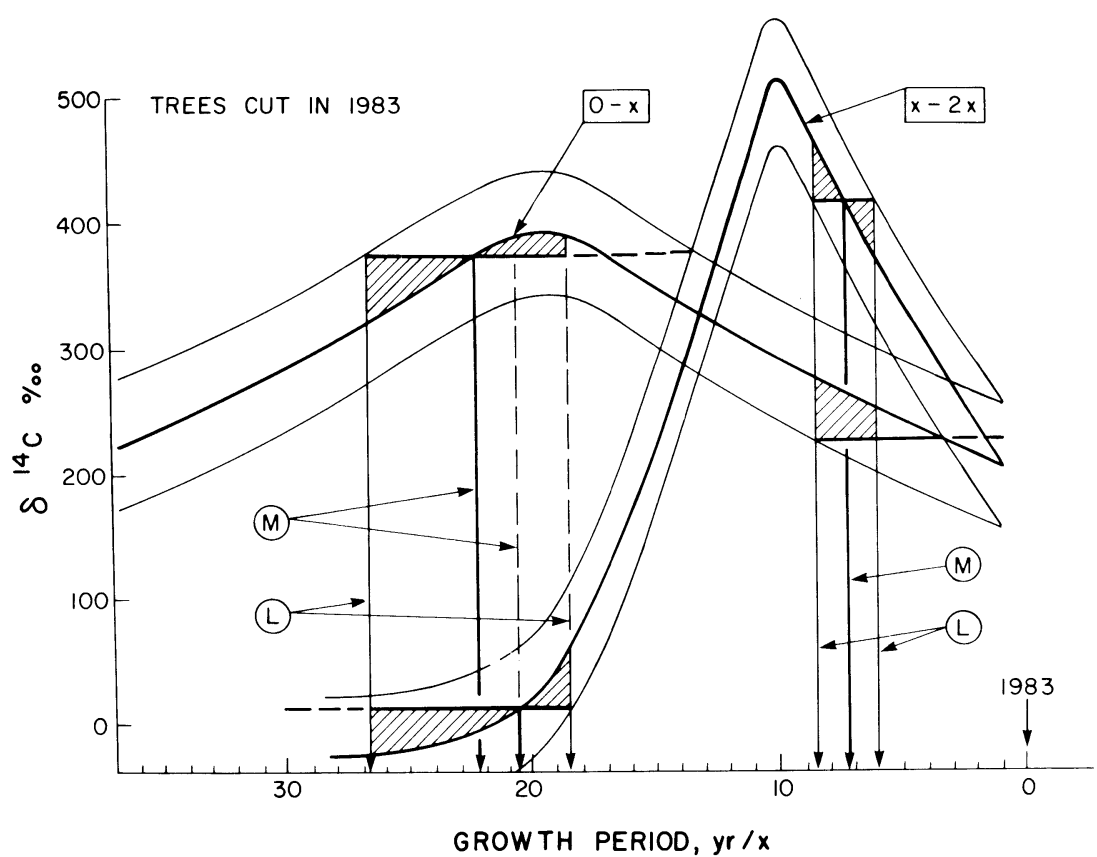

Fig 1. Growth periods $(\mathrm{yr} / \mathrm{X})$ vs the averaged ${ }^{14} \mathrm{C}$ activities over specific periods are shown for trees cut in 1983. Two examples are shown: the short growth period refers to tree 1-7, the long one to tree 2-1 (see Table 1).

mined in the following manner: if we assume a 10-year growth for the two segments, the measured ${ }^{14} \mathrm{C}$ activities have to be matched to a 10 -year average of sequential fallout activities (Table 2). For example, if a tree had its last growth year in 1983 , the first period $(0-\mathrm{X})$ will cover the years 1974 to 1983 , and the preceding one $(\mathrm{X}-2 \mathrm{X})$, the years 1964 to 1973 . The tree segment $(0-\mathrm{X})$ will then have a ${ }^{14} \mathrm{C}$ activity corresponding to the average ${ }^{14} \mathrm{C}$ activity of the fallout for the period of 1974 to 1983 . Similarly, the ${ }^{14} \mathrm{C}$ activity of the second segment $(\mathrm{X}-2 \mathrm{X})$ will correspond to the average ${ }^{14} \mathrm{C}$ activity of the fallout for the period $1964-1973$. The averaged ${ }^{14} \mathrm{C}$ data can be displayed graphically as growth years per segment vs integrated ${ }^{14} \mathrm{C}$ activities for the same period. Figure 1 thus shows two curves with averaged ${ }^{14} \mathrm{C}$ activities for various growth periods, one covering segments $0-\mathrm{X}$ and the other one X-2X.

The analytical error on both curves does not exceed $\pm 10 \% 0$. However, the estimated average value for each year may have a somewhat larger error. As not enough data exist for the Amazonian area, a maximum error of $\pm 50 \%$ was assumed, based among others, on the average amplitude of variations presented by Levin et al (1985). For the years 1963-65 (maximum bomb fallout) this error could be larger as the input was much more variable than during the pre- and post-bomb periods.

Growth periods can be read from Figure 1 which displays two exam- 
TABLE 3

Growth rates and extrapolated minimum ages of 11 trees from the Amazon Basin

\begin{tabular}{cccc}
\hline $\begin{array}{c}\text { Tree no. (see } \\
\text { Table 2 for tree } \\
\text { identification) }\end{array}$ & $\begin{array}{c}\text { Trunk radius } \\
(\mathrm{cm})\end{array}$ & $\begin{array}{c}\text { Growth rate } \\
(\mathrm{yr} / \mathrm{cm})\end{array}$ & $\begin{array}{c}\text { Minimum age* } \\
(\mathrm{yr})\end{array}$ \\
\hline $1-1$ & 32 & $30-40 / 3$ & 370 \\
$1-3$ & 32 & $>40 / 3$ & 480 \\
$1-5$ & 20 & $20 / 3$ & 133 \\
$1-6$ & 30 & $>40 / 3$ & 7400 \\
$1-7$ & 30 & $5-7 / 3$ & 70 \\
$2-1$ & 28 & $20-22 / 3$ & 196 \\
$2-2$ & 28 & $15-25 / 3$ & 64 \\
$2-3$ & 30 & $8-9 / 4$ & $63^{* *}$ \\
$2-4$ & 21 & $<10 / 3$ & 385 \\
$2-5$ & 33 & $35 / 3$ & $85^{* *}$ \\
$2-6$ & 38 & $9 / 4$ & \\
\hline
\end{tabular}

* See text for definition. sion.

** Matched on data in Table 2 rather than the curves of Figure 1. See text for discus-

ples. Note, that for growth periods of $<10 \mathrm{yr} / \mathrm{X}$, the $\mathrm{X}-2 \mathrm{X}$ curve shows very steep changes with time. Consequently, the error on the extrapolated growth period is $< \pm 2 \mathrm{yr}$, despite the $50 \%$ error. On the other hand, for growth periods $>20 \mathrm{yr} / \mathrm{X}$, both curves become rather flat and, as a result, the error increases to $> \pm 5 \mathrm{yr}$.

The measured values are reported in Figure 1 as horizontal bars with limits given by the error on the fallout curve. Ideally for either curve, we would have a match line ("M" in Fig 1) within the error limit ("L" in Fig 1). Such is the case for a tree with a large growth period (slow growing). The second example, a tree with small growth periods (fast growing) shows only one match line which satisfies the errors of both curves.

Estimated growth rates for the Amazonian trees and extrapolated minimum ${ }^{14} \mathrm{C}$ ages are summarized in Table 3 . A minimum age can be determined if the width of the tree rings decreases towards the center of the tree (Worbes, 1985). This appears to be most common but where a systematic increase in growth rate (mm/yr) occurs, maximum ages would be quoted.

It is interesting to note that tree numbers 2-4 and 2-6 (see Tables 1 and 3) have $0-X$ and $X-2 X{ }^{14} \mathrm{C}$ activities that do not match with the curves presented in Figure 1. Their growth periods were determined through matching against data in Table 2 and were found to be $<10 \mathrm{yr} / 3 \mathrm{~cm}$ and $\sim 9 \mathrm{yr} /$ $4 \mathrm{~cm}$, respectively. These results could indicate that these two trees did not have significant wood growth since 1976 and 1979, respectively, or alternatively, could suggest that they were not cut in 1983 as was assumed, but rather in 1976 and 1979. The latter explanation is less likely.

A comment on the ${ }^{13} \mathrm{C}$ data reported in Table 1 is appropriate. The majority of the trees show lower $\delta^{13} \mathrm{C}$ values in their most recent wood (segment $0-\mathrm{X}$ ). The trend is corroborated by other ${ }^{13} \mathrm{C}$ data obtained in a systematic analysis of $2 \mathrm{~cm}$ of radial segments of a tree trunk disk (A A Mozeto, $\mathrm{ms}$ in preparation). This decline reflects the enhanced uptake of increasing isotopically light atmospheric $\mathrm{CO}_{2}$ during photosynthesis. However, it remains unanswered whether this change reflects the global decrease of ${ }^{13} \mathrm{C}$ 
content in the atmospheric $\mathrm{CO}_{2}$ (Freyer, 1979) or is related to local changes and $\mathrm{CO}_{2}$ input from activities such as deforestation. Systematic studies of ${ }^{13} \mathrm{C},{ }^{18} \mathrm{O}$, and ${ }^{2} \mathrm{H}$ on ${ }^{14} \mathrm{C}$ "dated" trees are in progress to elucidate this question and to refine the age dating procedures.

\section{CONCLUSION}

Conventional dating techniques in general cannot be applied to the Amazon forest trees. The technique reported here is based on the determination of ${ }^{14} \mathrm{C}$ activities in two equal radial segments of wood from the outermost portion below the cambium of a tree trunk. The approach utilizes the anthropogenic ${ }^{14} \mathrm{C}$ fallout which occurred during the past 30 years or so and it is shown that the two measurements suffice to define within rather narrow limits the growth rate and the age of tropical forest trees. Efforts are presently undertaken to obtain on dated trees a ${ }^{14} \mathrm{C}$ fallout curve which is representative of the equatorial Amazon region.

Radiocarbon dating of trees from natural forests provides information on the length of time a species needs to grow to commercial size and is of economic interest where reforestation is undertaken. Growth rates of various tree species of the Brazilian Amazon Basin are also important for yielding data on applicable thinning regimes and felling cycles which is the basis for economically viable tropical forest management systems with sustained yield.

\section{ACKNOWLEDGMENTS}

This research was sponsored by FAPESP (The Sao Paulo Foundation for Research, grants no. 83/1023-7 and 83/2284-9), CNPq (The National Council for Scientific and Technological Development, grants no. 30.5795/85-QU, 40.8627/85-QU and 1.05.20.001/86), and by NSERC grants no. A7954 and SE-0175 to PF.

\section{REFERENCES}

Bormann, F H and Berlyn, G, eds, 1980, Workshop on age and growth rate determination for tropical trees, April 1-3, Harvard Forest, Petersham, Massachusetts, Proc: New Haven, Connecticut, Yale Univ Press.

Freyer, H D, 1979, Variations of the atmospheric $\mathrm{CO}_{2}$ content, in Bolin, B, Degens, E T, Kempe, S and Ketner, P, eds, The global carbon cycle: New York, John Wiley \& Sons, $\mathrm{p}$ $79-99$.

Levin, I, Kromer, B, Schoch-Fisher, H, Bruns, M, Münnich, M, Berdau, D, Vogel, J C and Münnich, KO, 1985, 25 years of tropospheric ${ }^{14} \mathrm{C}$ observations in central Europe: Radiocarbon, v 27, no. 1, p 1-19.

Polach, $\mathrm{H}$ and Singh, G, 1980, Contemporary ${ }^{14} \mathrm{C}$ levels and their significance to sedimentary history of Bega Swamp, New South Wales, in Stuiver, M and Kra, R S, eds, Internatl ${ }^{14} \mathrm{C}$ conf, 10th, Proc: Radiocarbon, v 22, no. 2, p 398-409.

Saliège, J F and Fontes, J C, 1984, Essai de determination experimentale du fractionnement des isotopes ${ }^{13} \mathrm{C}$ et ${ }^{14} \mathrm{C}$ du carbone au cours de processus naturels: Internatl Jour Applied Radiation Isotopes, v 35, p 55-62.

Stuiver, M, Rebello, A, White, J C and Broecker, W, 1980, Isotopic indicators of age/growth in tropical trees, in Borman, F H and Berlyn, G, eds, Age and growth rate of tropical trees: New directions for research: New Haven, Connecticut, Yale Univ Press, p 75-82.

Worbes, M, 1985, Structural and other adaptations to long-term flooding by trees in Central Amazonia: Amazoniana, v 9, p 459-484. 